\title{
O DESENHO DA GESTÃO DA TECNOLOGIA DA INFORMAÇÃO NAS 100 MAIORES EMPRESAS NA VISÃO DOS EXECUTIVOS DE TI
}

\author{
IT MANAGEMENT DESIGN AT THE TOP 100 BRAZILIAN COMPANIES, \\ ACCORDING TO THEIR CIOS
}

\author{
Leonel Cezar Rodrigues \\ Emerson Antonio Maccari \\ Universidade Nove de Julho (UNINOVE), Brasil \\ Sergio Alexandre Simões, \\ PricewaterhouseCoopers, Brasil
}

\begin{abstract}
The objective of this paper is to identify the design of IT management atn the top 100 Brazilian companies. The research method was a quantitative approach, using the descriptive-statistical method to describe the data collected through a questionnaire with 77 questions, based on the rationale of the IT management, proposed by Lutchen (2003). The main results indicate that: a) IT aligns with the basic processes of business, although not fully synchronized; b) IT management adheres to conformity systems (ITIL, COBIT), but does not show optimization of business processes; c) IT delivers the basic demands, but does not impose or use the best automated practices; and d) IT quality is based on documented processes, but lacks indicators to control and orient business improvement. One may infer that IT management, at the top 100
\end{abstract}

Recebido em/Manuscript first received: 10/08/2009 Aprovado em/Manuscript accepted: 03/12/2009 Endereço para correspondência/ Address for correspondence

Leonel Cezar Rodrigues, UNINOVE, Doutor em Administração pela Vanderbilt University, TN (USA) (1990), com concentração em Sistemas de ciência e tecnologia. Professor e pesquisador do Programa de Mestrado e Doutorado em Administração - PMDA na Universidade Nove de Julho. E-mail: leonelcz@gmail.com

Emerson Antonio Maccari, UNINOVE, Doutor em Administração pelo Programa de Pós-Graduação em Administração - PPGA/FEA USP com Estágio doutoral na University of Massachusetts Amherst - USA. Mestrado em administração na Universidade Regional de Blumenau - FURB. Graduado em Ciências da computação e em Administração pela mesma universidade. Professor do programa de pós-graduação em administração - PPGA/UNINOVE E-mail: emersonmaccari@gmail.com

Sergio Alexandre Simões, Doutorando no Programa de Administração - PMDA na Universidade Nove de Julho. Pós graduado em Administração de Empresas e Gestão Empresarial pela FCA-ESAN (1999). Engenheiro Eletrônico pelo Centro Universitário da FEI (1994) e atualmente diretor da área de Advisory Services da PricewaterhouseCoopers. Professor coordenador do MBA em Gestão de Segurança da Informação da FIAP - SP. E-mail: sergio.a.simoes@uol.com.br

ISSN online: 1807-1775

Publicado por/Published by: TECSI FEA USP - 2009 
Brazilian companies is essentially based on standard IT conformity systems, under the rationale of solution providers, and not as a business innovator or rule breaker. Thus, in spite of aligning and responding to business basic demand, IT management still does not show clear signs of alignment with the evolving nature of business models, needed to sustain business performance.

Keywords: Information Technology; Innovation; IT Alignment; IT Management; IT Services; IT Quality;

\section{RESUMO}

O objetivo desse artigo é identificar o desenho do gerenciamento da TI nas 100 maiores empresas brasileiras. A pesquisa teve uma abordagem quantitativa e utilizou-se do método estatístico-descritivo para apresentar os dados, coletados por meio de questionário estruturado fechado, com 77 questões baseadas na gestão da TI, dentro da lógica argumentativa de Lutchen (2003). Os principais resultados indicam que: a) há um alinhamento com os processos básicos de negócio, porém, com mostras de dessincronias; b) a gestão está orientada para os sistemas de conformidade (ITIL, COBIT), mas sem otimização dos processos de negócio; c) a TI entrega as demandas básicas, porém sem estrutura para impor e usar as melhores práticas automatizadas; e d) a qualidade apresenta processos documentados, porém com falta de indicadores para o desenvolvimento dos negócios. Infere-se do quadro da pesquisa que a gestão da TI é conduzida essencialmente com base nas metodologias padrões de gestão de TI, muito mais dentro da lógica de fornecedora de soluções do que dentro dos princípios da inovação ou quebra de regras dos negócios. Assim, apesar de alinhar-se e responder às demandas básicas dos negócios, a gestão da TI não dá ainda mostras claras de avanço de aderência à natureza evolutiva dos modelos de negócios necessária à sustentação de desempenho desses.

Palavras-chave: Tecnologia de Informação; Inovação; Alinhamento de TI; Gestão da TI; Serviços, Qualidade em TI;

\section{INTRODUÇÃO}

Os resultados da pesquisa global da McKinsey, sintetizada por Roberts; Sikes (2008), mostram que os executivos seniores das empresas e os executivos da Tecnologia de Informação querem que a TI sirva melhor às estratégias de negócio de suas empresas, mas o desempenho da TI ainda está muito aquém de realizar seus sonhos. Nesta pesquisa, a grande maioria dos respondentes ressalta como críticos, os riscos que suas respectivas empresas correm por causa de inovações disruptivas provocadas tanto por mudanças nas expectativas dos consumidores, capacitadas por meio de novas tecnologias e da tecnologia de informação, quanto por serviços diferenciados. Além disso, há um medo generalizado, de perder vantagens competitivas, originado na redução significativa de custos de manufatura ou de entrega de produtos e serviços mais eficientes por parte dos competidores. Apesar disso, a TI tende a concentrar-se na eficiência de seus processos, em apresentar problemas de alinhamento, a entregar somente as demandas básicas, em apresentar problemas de capacitação e a diminuir seus investimentos gerais, vistos simplesmente como custos.

A pesquisa feita por Craig; Tainaikar (2006) entre os líderes das maiores empresas do mundo, acerca do papel e formas de gestão da TI indica que a TI pode ser usada como ferramenta competitiva. Mas para administrar a TI com esse objetivo é preciso uma abordagem diferenciada que muitas empresas tem dificuldades de 
O desenho da gestão da tecnologia da informação nas 100 maiores empresas na visão dos executivos de TI

implementar, seja porque elas não conseguem ver o potencial da TI para inovação, seja porque elas não conseguem distinguir entre a inovação que a TI pode prover e os serviços básicos associadas à função da TI. Um exemplo de como a TI pode ser usada para influenciar o desempenho dos negócios pode ser visto na Charles Schwabe, uma das maiores empresas de serviços financeiros do mundo. Cresceu rapidamente, a partir do início da década de 1990, baseada na capacidade de solução de seu sistema de TI (SHPILBERG et al., 2007). Tecnologia da Informação era o único fator que permitia à jovem empresa subplantar suas rivais, por conseguir abaixar seus preços muito além dos que praticavam seus competidores. Apesar da tendência da TI adquirir um papel de commodity, até o final da década passada, a Schwabe havia se transformado na empresa de serviços financeiros de massa de menor taxa de serviços, comparativamente às empresas tradicionais do ramo. Essa façanha foi conseguida graças às suas capacidades de oferta de serviços financeiros inteiramente on-line, um produto que inovou o modelo e os processos de negócio da Schwabe. Traduzindo as lições da trajetória da Schwabe para o presente estudo, pode-se dizer que a lógica que permeia a análise do contexto corrente da TI e seu papel nas empresas concentra-se no formato da gestão de suas atividades.

\subsection{Problema de pesquisa}

Como muitas empresas conscientes do papel e importância da TI para seus negócios, a rede de conveniência Seven Eleven Japonesa fez efetivos investimentos em TI e administra seu portfólio de TI para dar contínuo suporte à estratégia de seu negócio (WEILL; ARAL, 2006). Ao atender às práticas e preferências locais, a empresa pode suceder na introdução de novas linhas de produtos, em suas unidades. Por exemplo, uma unidade típica da rede da Seven Eleven adiciona 70\% de novos itens para venda a cada ano, uma taxa maior que qualquer outra loja de conveniência no Japão. Essa estratégia tem ajudado a dobrar a média diária de vendas da rede desde 1977. O desempenho da Seven Eleven é expressivamente ilustrativo da importância da TI e de suas funções para “agilização” dos processos operacionais e para a eficácia da estratégia competitiva da empresa. Parece claro que nessa empresa, a TI além de ser eficiente na disponibilização de aplicativos e soluções corretos (entrega), está plenamente alinhada com a estratégia de seu negócio, tornando-se instrumento central, tanto para decisões operacionais quanto para decisões estratégicas. Verificar, portanto, como a TI está sendo administrada, isto é, o desenho de seu gerenciamento, em especial nas grandes empresas líderes na economia do país pode mostrar a criticalidade das relações entre as demandas de negócio e o exercício das funções da TI nas empresas.

O uso da TI, seja como instrumento de entrega de serviços básicos para as atividades de negócio das empresas, seja como instrumento de inovação, ou como instrumento de modelagem de negócios, na maioria das empresas parece estar ainda longe de atingir seu apogeu contributivo. Apesar dos executivos de negócios e dos executivos de TI concordarem, nos inúmeros trabalhos de pesquisadores renomados, de que a TI pode ter um papel mais crítico e que pode fazer mais para o desempenho dos negócios, os resultados indicam que parece haver uma dicotomia entre as prioridades desta e as demandas implícitas dos negócios. As grandes empresas nacionais, por apresentarem bom desempenho, parecem ter seus modelos de negócio ajustados e eficientes. Seria esse o caso das 100 maiores empresas sediadas no Brasil? Como estão desenhando, os executivos de TI dessas empresas, o gerenciamento de suas respectivas 
áreas, para alinhar, gerir, entregar e garantir a qualidade dos serviços de TI para a área de negócios de suas empresas?

Neste contexto, o objetivo desse artigo é determinar o desenho da gestão da TI, sob os principais fatores adjetos às dimensões de alinhamento, gestão, entrega e qualidade dos serviços de TI, nas 100 maiores empresas sediadas no Brasil, classificadas no Guia Exame - Maiores e Melhores/2008.

\section{REVISÃO DA LITERATURA}

A realidade dos negócios mostra uma atuação dúbia da TI, em relação às suas funções exigidas pelas práticas administrativas de negócios e as práticas gerenciais da função TI. Os executivos de negócio precisam da TI ajudando-os em suas metas. Os gerentes de TI entendem tais metas como sua prioridade, aderindo a elas como sua função principal. Esses comportamentos tornam as atividades correntes da empresa 0 foco e preocupação mais importantes dos executivos da TI. Isso tem absorvido o tempo e limitado as funções e o papel desses executivos para dedicarem-se à inovação nos negócios. Em adição, tornam a TI praticamente ausente da liderança na construção de diferenciais competitivos para o negócio da empresa. A TI, porém, pode atuar de forma incisiva exercendo papéis distintos na empresa.

\subsection{Papel da TI nas organizações}

Desde que Lutchen (2003) apontou a grande lacuna funcional da TI na construção de negócios eficientes e lucrativos, muitos autores têm se debruçado sobre o papel da TI nas organizações. O próprio Lutchen critica a falta de visão dos executivos de TI de verem-na como um negócio. Em sua origem, e eventualmente dadas as características de formação dos CIOs, suas preocupações vão para dois extremos: ou para a base operacional, determinando a planejamento das atividades táticas e implementação da infra-estrutura de TI; ou para o topo, focando o desenvolvimento das estratégias de TI e seu alinhamento com as estratégias do negócio. No meio desses dois extremos, situa-se o gap da TI, que envolvem a tradução e o ligamento das soluções de TI às necessidades do negócio, a integração dos sistemas e otimização de suas aplicações e a direção (liderança), medida e controles de desempenho. Esse conjunto de funções Lutchen chama de espectro da TI.

A eficiência da TI, no entanto, está na forma de sua organização e de sua condução, dentro dos parâmetros de um negócio e, na visão de Lutchen, essas são exatamente as funções medianas que ligam a base operacional ao topo estratégico. Para fazê-lo, Lutchen (2003), advoga seis passos críticos: (1) os CIOs devem entender o negócio da empresa e trazer a TI para os fundamentos desse negócio; (2) os CIOs devem administrar a TI como um negócio distinto que suporta os objetivos da corporação e sustenta seus lucros; (3) os CIOs devem ligar a estratégia de TI à do negócio de forma pragmática, ajustando seus processos com qualidade e eficiência; (4) os CIOs devem ajudar as unidades de negócio a definir suas necessidades (e riscos), melhorando seus serviços por meio de uma gestão controlada e eficiente; (5) os CIOs devem consolidar na TI a cultura de serviço ao cliente, com qualidade e voltada para resultados; e (6) os CIOs devem ser recompensados, baseados no retorno que as iniciativas de TI dão para os lucros da empresa. 
O desenho da gestão da tecnologia da informação nas 100 maiores empresas na visão dos executivos de TI

Smith; McKeen (2006), por exemplo, apontam como resultado de suas pesquisas que haveria uma tendência nos próximos anos, de a TI aumentar sua flexibilidade pela maior adaptação de suas atividades, processos e estrutura, aos interesses dos negócios. Assim, os executivos de TI passariam a ser mais estratégicos em seus papéis, isto é, eles iriam passar a contribuir mais para a formulação das estratégias de negócio em suas empresas. Isso também os ajudaria a alterar a imagem da TI nas empresas, já que tais papéis inseririam mais definitivamente a TI nas funções de transformação e inovação dos negócios.

Esse novo papel parece estar igualmente embutido na lógica por trás da asserção de Prahalad (2006) quando defende o potencial dos CIOs como facilitadores da realização das estratégias de negócio por meio de processos operacionais de excelência na TI. Suas funções seriam a de garantir a transformação dos negócios mediante as estratégias alinhadas da TI.

A TI está mudando na dimensão de suas funções e papéis, segundo Mahoney (2007). Tais mudanças deslocam o foco tecnológico da TI para os negócios e suas necessárias soluções. O autor aponta cinco áreas de mudança. Uma mudança indica que a TI vai preocupar-se mais com sua própria re-organização, especialmente gerir terceirizações e entregar serviços. A segunda mudança, em conseqüência, indica que a TI vai preocupar-se mais com a gestão dos recursos do que com investimentos em infraestrutura. O terceiro foco de mudança estaria na construção de competências, ou de novas competências, para a TI, já que ela vai precisar entender cada vez mais dos processos de negócios, da gestão de recursos e de suas relações. A quarta área de mudança concentra-se na redução das complexidades objetivando aumentar a eficiência e flexibilidade dos processos de negócio. E a quinta área de mudança é a maior atenção que a TI deve dar às parcerias (para terceirizações e offshoring) que deverão aumentar os ganhos para os negócios (rapidez de soluções a menores custos).

É notável, que em todos os autores, há uma observação clara do movimento da TI nas organizações em direção a um papel mais ativo nos negócios. Takanen (2008) achou em suas pesquisas que esse panorama já mudou em parte. O papel dos CIOs de empresas baseadas ou de uso intensivo de TI, já mudou para o de executivos de negócios. Nas outras empresas, no entanto, perdura a dificuldade de transformar os CIOs com orientação técnica em executivos de negócios, com sugere Lutchen (2003). Adicionalmente, Takanen (2008) aponta a grande dificuldade dos CIOs participarem do processo de planejamento e decisão das estratégias da empresa, o que poderia ajudar muito a criação de valor pela TI e a captura econômica desse valor pelo negócio da empresa.

A pesquisa de Craig e seus colegas mostra que a TI exerce papéis distintos nos processos empresariais, dependendo do que ela é projetada a fazer. Os autores agrupam a influência da TI em três papéis, baseados na relação e suporte a produtos e processos de negócio. São eles: fornecedora de serviços, instrumento gerencial alinhado aos interesses do negócio e ferramenta de inovação, ou diferenciador competitivo (CRAIG et al., 2007).

(a) TI como Fornecedora de serviços. Este é o primeiro papel, mais comum, que a TI exerce dentro da empresa. Neste caso, a TI foca basicamente as questões de informação para a empresa, mas mantém-se afastada ou à distância dos negócios, sem 
um envolvimento direto e claro nos processos e no desempenho final. O papel de fornecedora de serviços, incluindo aplicativos de suporte à competência central do negócio, sistemas que respondem aos requisitos das demandas regulatórias, e-mail e serviços de Internet, leva a TI a focar a redução de custos operacionais, a garantia da qualidade e a manutenção de níveis ótimos de serviços transacionais.

Craig et al, (2007) dizem que os papéis da TI podem ser associados à visão de negócio da empresa. Por exemplo, investimentos feitos em TI para mudar as regras do negócio ou para oferecer novos produtos e serviços, indicam uma estratégia de negócio visando à quebra de regras do negócio (inovar disruptivamente). Investimentos feitos em TI para baixar os custos ou aumentar a produtividade, como automação dos processos de negócio, indicam uma estratégia de negócio visando a vencer a corrida (inovar). E investimentos feitos em TI para manter os serviços básicos de TI, indicam uma estratégia de negócio visando meramente a permanecer na corrida (sobreviver ou manter a posição).

Desta forma, o papel de fornecedora de serviços está associado às capacidades mínimas necessárias para manter os negócios na corrida, segundo Craig; Tinaikar (2006). Tais serviços exigem capacitações de baixo risco, necessários somente para manter o negócio na corrida, por isso mesmo, são investimentos de risco mínimo. Por serem de risco mínimo e, teoricamente, de retorno razoáveis, são o tipo de investimentos preferidos pelos executivos. Pela natureza dos serviços providos pela TI para esse tipo de investimentos, porém, parece haver um alinhamento automático da TI às estratégias corporativas, o que de fato, pode não acontecer, já que o provimento desses serviços pode acontecer de forma independente do alinhamento.

(b) TI Alinhada com o Negócio. Este é um papel menos comum e por isso, mais difícil e mais exigente em termos de capacidades requeridas da TI. Neste caso, a TI alinha-se, isto é, envolve-se com os interesses do negócio e ajuda a empresa a alcançar suas metas. Aqui o simples alinhamento não é suficiente para considerar-se que a TI esteja contribuindo efetivamente para o negócio, dizem os autores. É preciso que a TI tenha um elevado envolvimento ou integração com a estratégia de negócio. Não é suficiente que a estratégia de TI tenha alguma influência sobre a formulação e execução da estratégia de negócio. Ou mesmo, que a estratégia de TI, apesar de coerente com a de negócio, venha a reboque desta última. Para estar alinhada ao negócio, é preciso que a TI tenha seus talentos e capacidades focados nos projetos demandados ou de interesse da área de negócio e que seus projetos sejam originados em parceria, mas sob a liderança da TI.

O alinhamento da TI às estratégias de negócio como demandante ou direcionador dos investimentos, por outro lado, envolve riscos de nível mediano. São investimentos que inovam os serviços básicos, diminuem os preços e aumentam a eficácia do processo de tomada de decisão e a flexibilidade dos processos de negócio. Esses investimentos ajudam o negócio a operar de forma inovadora e com uma produtividade significativamente superiora dos competidores. Por sua natureza, tais investimentos são igualados ou eventualmente vencidos pela concorrência, mas servem para a empresa temporariamente vencer a corrida. A tangibilidade desses investimentos pode ser avaliada pelo retorno em inovações que a TI passa a oferecer para os processos de negócio da empresa. 
O desenho da gestão da tecnologia da informação nas 100 maiores empresas na visão dos executivos de TI

(c) TI como Diferenciador Competitivo. Este é o papel mais incomum e inusitado da TI. Neste caso, a TI projeta-se além das necessidades dos negócios, considera tendências tecnológicas e o entorno competitivo para assumir um papel proativo na formulação da estratégia do negócio. Da Administração da TI requer-se atenção redobrada a seu cenário tecnológico para incorporar e criar novas fontes de vantagens competitivas. Para transformar-se em alavanca do diferencial competitivo, a TI precisa identificar com antecedência oportunidades externas, capazes de adicionar valor ao negócio pela incorporação de produtos, serviços ou processos novos não imaginados e de difícil reprodução pela concorrência.

Mais difícil de administrar, neste último papel, os investimentos caem numa categoria de alto risco (e também de alto retorno), que foca na mudança das regras da corrida (ou nas regras do negócio), no setor em que opera a empresa. Tais mudanças são inovações que abrem novos mercados, desenvolvem novos processos ou oferecem novos produtos ou serviços, essencialmente diferentes e mais desejáveis, do que os da competição. Investimentos nessa categoria são disruptivos e dão mais diferenciação competitiva e sustentabilidade à empresa e, por isso, emprestam à TI, o papel de quebradora de regras. Investimentos nessa categoria requerem alinhamento das capacidades e soluções da TI, mais à visão de negócio dos executivos, isto é, ao conceito ou modelo de negócio usado pela empresa, do que alinhamento simples às estratégias corporativas.

\subsection{Investimentos em TI}

Sob o ponto de vista científico, pode-se questionar a simplificação dos resultados de desempenho pela lógica dos investimentos. Pesquisas do Centro de Estudos em TI do MIT mostram que a infra-estrutura de TI e aplicativos para processos transacionais consomem $72 \%$ de todo o investimento feito pelas empresas em TI (WEILL et al., 2002; WEILL; ARAL, 2006), enquanto as áreas informacional e estratégica consomem os restantes 28\%. Por outro lado, a pesquisa do Instituto McKinsey, coletou respostas de 9.345 executivos no mundo todo e indica que 53\% deles reconhecem a inovação como a mais importante capacidade para crescer (MARWAHA et al., 2005). Parece haver aí uma dicotomia entre a ação e o pensamento estratégico desses executivos de TI no desenho do gerenciamento de suas áreas, mas que pode ter explicações em seus respectivos contextos.

Weill et al. (2002) realizaram uma pesquisa com as 140 maiores empresas no mundo para determinar as áreas e percentuais de investimentos em TI. Os autores acharam quatro áreas de investimentos básicos: infra-estrutura, transacional, informacional e estratégica. Nesta pesquisa a infra-estrutura era a área que estava recebendo o maior volume de investimentos, com 54\% do total. Em seguida, vinha a área informacional (aplicativos para gerenciamento da informação em nível médio, controle, gestão da qualidade, etc.), com 20\% dos investimentos. Finalmente, vinha a área transacional (aplicativos e sistemas para gestão da produção, aumento da produtividade, emissão de notas, etc.) e a estratégica (inovação, mudanças, agregação de valor, vantagem competitiva, etc.), ambas com $13 \%$.

Essa mesma pesquisa foi repetida em 2006, com os mesmos elementos e parâmetros (WEILL; ARAL, 2006). Os resultados indicaram uma leve mudança de 
orientação nos investimentos. Agora, todas as áreas de investimento mostradas na pesquisa anterior tiveram diminuição, exceto a área transacional. Nessa área, as empresas duplicaram os investimentos. A área estratégica baixou para $11 \%$, a informacional para $17 \%$ e a de infra-estrutura foi para $46 \%$. Os resultados dessas pesquisas mostram claramente que a primeira preocupação dos executivos das grandes empresa, em relação à TI, é com a infra-estrutura. É preciso ter capacidade de processamento e comunicação antes de qualquer coisa. Em segundo lugar, na primeira pesquisa, a tônica dos investimentos em TI, após a infra-estrutura, era o controle dos processos, expressa pelos investimentos na área informacional. Essa área serve ao sistema de operações táticas, comandado pelos gerentes em nível médio (níveis B e C). Recentemente, porém, a área transacional tornou-se um foco mais importante de investimentos, após a infra-estrutura, possivelmente por causa da preocupação das empresas em abaixar custos operacionais e em aumentar a produtividade. Por fim, é importante notar-se também que a área estratégica, a que se preocuparia, em princípio, com a geração e incorporação de inovações, foi a que recebeu menor volume de investimentos nos últimos anos.

Se considerarmos os investimentos dentro da visão de "manter-se na corrida," "vencer a corrida" ou "quebrar as regras" do negócio do setor, a observação dos resultados dos investimentos em TI, achadas pelos autores, parecem voltar-se para sustentar a simples manutenção dos negócios na corrida. TI, quando empregada de forma inteligente, pode ajudar as organizações a dar grandes saltos em produtividade e redefinir a forma de competir em seu setor. A essência do bom investimento é, como colocam Farrell et al. (2003) saber onde e quando investir, isto é, saber selecionar os investimentos em TI que criarão uma vantagem sustentável e diferenciada.

\subsection{Alinhamento da TI às estratégias de negócio}

As contínuas pressões do entorno competitivo das empresas representam desafios permanentes à habilidade dos executivos e gerentes de responderem rapidamente àqueles desafios. Tal habilidade assenta-se sobre a disponibilidade de infra-estrutura sofisticada e o grau de flexibilidade da TI de que dispõem. Empresas grandes e experientes confrontam-se constantemente com o problema de coadunar as estratégias emergentes de negócio e os recursos de TI que devem suportá-las (PRAHALAD; KRISHNAN, 2002). Os autores apontam empresas, tais como Cemex, Keebler, Amazon and GE Lighting, prestaram atenção às mudanças em seu ambiente e no cenário tecnológico e criaram novas capacidades em suas infra-estruturas de TI. Assim, não apenas conseguiram alinhar a TI com a estratégia de negócios, mas fizeram a TI integrar-se à estratégia de seus negócios. "Isto é uma contínua e dinâmica sincronização das competências intrínsecas dentro da infra-estrutura de informação e as exigências da estratégia.” (PRAHALAD; KRISHNAN, 2002, p. 26).

A pesquisa de Prahalad; Krishnan (2002), com mais de 500 executivos em empresas do mundo todo, apontou infra-estrutura de TI como um recurso aquém dos anseios e necessidades de mudanças dos executivos. A pesquisa avaliou cinco grandes parâmetros (Grau de mudanças na Indústria, Direção estratégica, Capacidade para mudar da empresa, Qualidade da infra-esturura e Capacidade colaborativa dentro da organização) numa escala de 0 a 5 . As respostas, nessa escala, apontaram uma média de 2,5, onde 5 seria a apropriação da TI percebida como ideal pelos respondentes. Os 
O desenho da gestão da tecnologia da informação nas 100 maiores empresas na visão dos executivos de TI

resultados indicam uma grande distância entre a realidade e o que desejariam os gerentes de como a TI estivesse atuando. Para atingir a base informacional ideal, os autores aconselham que para "entender a capacidade, impedimentos e riscos em sua infra-estrutura [de TI], os gerentes de negócios e os gerentes de TI necessitam de uma estrutura de trabalho comum" (PRAHALAD; KRISHNAN, 2002, p.29). As organizações que ainda não incorporaram o sincronismo dinâmico entre a estratégia de TI e a de negócio como elemento condicionante de sua cultura precisam iniciar este processo de forma planejada.

A sincronia dinâmica das estratégias, no entanto, não é suficiente para garantir efetividade da TI aos interesses do negócio, dizem Shpilberg et al. (2007). É preciso tomar cuidado com algumas armadilhas do alinhamento. Por alinhamento entende-se o grau de compromisso do grupo de TI para com as prioridades do negócio, a alocação de recursos e a realização, tanto de projetos, quanto a entrega de soluções, consistentes com os objetivos do negócio. Os autores alertam para problemas de ineficiência associada às competências do grupo de TI, não ao seu alinhamento. Por exemplo, quando o grupo de TI entende as prioridades do objetivo do negócio, mas não é capaz de responder eficazmente, com tecnologias ou soluções adequadas, então tem-se uma armadilha do alinhamento. Os autores sugerem atenção a três fatores determinantes da eficácia da TI para os negócios: ênfase na simplicidade, terceirização correta e eficiente, e atribuição adequada de responsabilidades. Laartz et al.(2003) sustentam que se há ineficiência geral na execução dos projetos (em tempo e em orçamento) pode haver ineficácia do alinhamento da TI a objetivos de negócio específicos e importantes, mas a TI, ainda assim, poderá estar alinhada. É preciso olhar as competências, não necessariamente a estratégia de alinhamento em uso.

Tanto a sincronia dinâmica, quanto as armadilhas, apontadas pelos autores acima, são importantes elementos do alinhamento, mas não indicam como medir se uma empresa possui a gestão de sua TI alinhada com as estratégias de negócio. Luntchen (2003) identifica os parâmetros essenciais do alinhamento da TI com os negócios em quatro grandes grupos: alinhamento, gestão, serviços e qualidade.

\subsection{A gestão da TI - Entrega e Qualidade}

As soluções de melhoria da gestão da TI nas empresas têm levado essas a combinarem gestões, compartilharem decisões e criarem a governança corporativa para a TI (FAGUNDES, 2009). Tais ações tem resultado em diminuição de custos, facilidade de mudança nos processos de negócio e aumento da flexibilidade dos sistemas de TI. Ainda assim, a centralização da TI com outras funções em unidade de serviços compartilhados pode distanciar as unidades de negócio das capacidades de TI de que precisam (MARWAHA; WILLMOTT, 2006). Para dar velocidade e capacidade inovadora às empresas, a TI deve ser administrada como são administrados seus negócios: com processos, regras, metas e com parâmetros e métricas de controle mensuráveis para as várias unidades da empresa (LUTCHEN, 2003). Mas acima de tudo, tais elementos precisam ser bem documentados, automatizados e disseminados pelas unidades, segundo as melhores práticas do mercado.

Operacionalmente, as empresas deveriam integrar os serviços básicos da TI com o conjunto das operações de caráter administrativo e administrá-los com eficiência de escala. Serviços que ajudam os negócios a desenvolverem novas soluções ou novos 
produtos devem estar integrados diretamente a esses negócios. Em essência, as empresas deveriam investir os recursos de TI não apenas para manter os serviços de TI operando, mas para gerar inovações e desenvolver produtos que ajudem a abrir novos mercados (LUTCHEN, 2003).

Rapidez, produtividade e inovação são características difíceis de serem construídas por suas naturezas conflitantes. Rapidez e produtividade são congruentes, mas adicionar a capacidade de inovação simultaneamente parece dicotômico. Marwaha; Willmott (2006) sugerem uma constante migração de níveis. Uma vez identificada a inovação é preciso migrar rapidamente para os padrões do negócio. Assim, a inovação, como solução para um processo ou um novo produto deve alinhar-se à estratégia do negócio para garantir alcance de metas. O seguinte passo é a migração do alinhamento da TI com o negócio para a produção em escala. A migração, porém, precisa estar assegurada pelas melhores práticas de gestão de processos, como o Information Technology Infra-structure Library (ITIL), Control Objectives for information and related Technology (COBIT) e o The Open Group Architecture Framework (TOGAF) e outros. Desta forma, pode-se estabelecer e aplicar os indicadores de controle da qualidade, mantendo ganhos de produtividade (BLOKDIJK; MENKEN, 2008). Por fim, deve-se usar a reversão do processo para aumentar a capacidade competitiva, isto é, migrando da produção em escala para o alinhamento da TI com as estratégias do negócio e inovação. Esses processos requerem um desenho para o gerenciamento da TI de forma a garantir os serviços demandados em escala e em qualidade satisfatórias.

\section{METODOLOGIA}

A pesquisa do presente artigo foi desenhada com uma abordagem quantitativa. $\mathrm{O}$ arcabouço da pesquisa que orientou o questionário obedeceu à estrutura do livro de Lutchen (2003). Luntchen advoga que para ser eficiente, a TI deve ser administrada como um negócio. Para tanto, o autor agrupa sob quatro temas centrais - alinhamento, gestão, serviços e qualidade - os fundamentos orientadores da gestão da TI. A estruturação das perguntas obedeceu à lógica do espectro de Lutchen, já discutido anteriormente. A razão principal na pesquisa original foi a de verificar o nível de maturidade da gestão de TI nas empresas pesquisadas. Para isso é necessário estabelecer uma lógica estruturante para a pesquisa. Decidiu-se, em conseqüência, utilizar a proposta de Lutchen, como modelo de maturidade em gestão de TI. Em outras palavras, perfis da gestão de TI desejáveis seriam os que se aproximassem ou contivessem as características gerenciais explícitas no espectro de Lutchen. Assim, seria necessário fazer uma varredura para conhecer as práticas de gestão de TI com os executivos de TI, envolvendo as atividades de topo (em nível estratégico), as atividades da base operacional (ajuste tático e excelência operacional) e as atividades medianas que caracterizam o gap de entrega da TI. A busca das informações sempre foi direcionada para o que os CIOs estão fazendo em termos das funções básicas da TI (alinhamento, serviços, qualidade e segurança -,ASQS).

Deste desenho metodológico, surgiu o presente trabalho, que se debruça sobre os resultados do perfil administrativo, por análise, não do espectro de Lutchen, mas das práticas que caracterizam a forma de entrega das atividades de TI (ASQS). Para cumprilo, um questionário estruturado, semi-disfarçado, com perguntas fechadas, foi enviado a 
O desenho da gestão da tecnologia da informação nas 100 maiores empresas na visão dos executivos de TI

100 executivos de Tecnologia de Informação das 100 maiores empresas do Brasil, listadas na Revista Exame das Maiores e Melhores de 2008.

As empresas pesquisadas pertencem a 10 segmentos da atividade econômica, educação, envolvendo: Petróleo, Óleo e Gás; Educação; Serviços; Indústria Manufatureira; Varejo; Saúde; Telecomunicações; Indústria do Consumo; Bancos e Financeiras; e Governo.

Todos os 100 executivos responderam ao questionário. Para o processamento das informações foi utilizada a Planilha Excel e para os casos inferenciais (não objeto dessa pesquisa), o software estatístico SPSS. Para essa pesquisa, apenas o primeiro instrumento de processamento foi utilizado, já que o método utilizado foi o estatísticodescritivo.

\section{RESULTADOS}

Como indicado na metodologia, as empresas pesquisadas pertencem ao quadro das 500 maiores empresas do Brasil destacadas na 34a edição do anuário MELHORES E MAIORES da revista EXAME em 2008. Dessas, foram selecionadas as 10 maiores empresas de cada segmento (Consumo, Educação, Finanças, Governo, Manufatura, Petróleo, Serviços, Saúde, Telecomunicações e Varejo) por serem os segmentos mais representativos da economia do país devido à sua participação relativa na composição do Produto Interno Bruto nacional. Genericamente, 62\% das empresas pesquisadas são de capital fechado e 32\% de capital aberto. 18\% delas estão sujeitas aos ditames da lei Sarbanes-Oxley de conformidade e transparência. Apesar de se reconhecer que a governança corporativa pode ter influência distinta do desempenho de um CIO isolado, para efeitos desse trabalho, considera-se o desenho da gestão de TI resultante, em termos de ASQS, independentemente de sua liderança.

É de se notar ainda que em termos de “momentum” do negócio das empresas selecionadas, 74\% dos respondentes indicaram que em 2008, sua empresa esteve em processo de expansão de mercados, isto é, aumentando diretamente sua participação relativa no mercado em que atua, ou aumentando o portfólio de produtos para aumentar sua presença no mercado. Em adição, essas empresas estão crescentemente dependentes da Tecnologia da Informação, pois, em média, 91\% dos seus funcionários utilizam-se da TI como uma ferramenta para suas tarefas de rotina.

Em relação ao perfil do executivo responsável pela TI, a pesquisa mostrou que todos possuem experiência acima de 16 anos em gestão de TI e 75\% deles restringem o âmbito de sua atuação ao Brasil. Hierarquicamente, é significante apontar que $42 \%$ dos executivos de TI pesquisados reportam-se ao Executivo principal e 33\% deles ao Executivo de Finanças. Os restantes 25\% reportam-se ou a CIOs internacionais ou a outros Departamentos em suas empresas.

Para simplificar a grande ordem de pequenos achados da pesquisa, decidiu-se por organizá-los, para as finalidades deste artigo, nos principais achados segundo os quatro temas pesquisados (alinhamento, gestão, serviços e qualidade). Em segundo lugar, atém-se somente às principais evidências, embutindo os pequenos achados nessas evidências, permitindo assim, apontar o perfil do desenho dos executivos de TI para o gerenciamento de suas áreas. 


\subsection{Alinhamento}

Quando perguntados se o plano de TI é formal, atual, divulgado e alinhado ao negócio, as respostas indicaram que 63\% deles possuem planos formais de TI e estão alinhados com o plano de negócios (Gráfico 1).

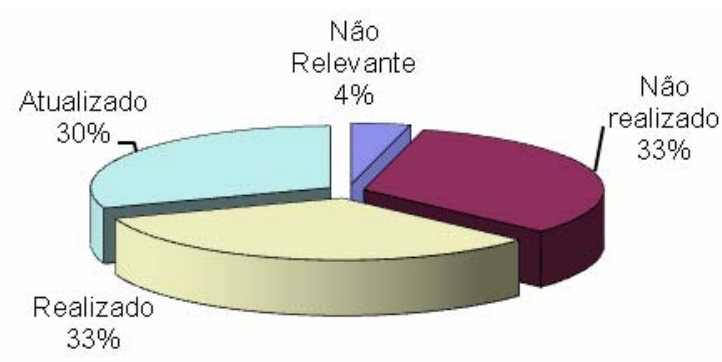

\section{Gráfico 1.- Alinhamento do Plano Estratégico de Negócios com o de TI}

Fonte: dados da pesquisa

É de se notar, contudo, que apenas 30\% atualizaram seus planos. Por outro lado, $37 \%$ dos executivos de TI não o realizaram ou não o reconhecem como importante. Essas respostas, quando confrontadas com os processos ou instrumentos de controle e monitoramento, replicam em essência, a aparente "dessincronia" de alinhamento entre a TI e a área de negócios. As práticas de controles de TI (Gráfico 2) poderiam garantir alinhamento.

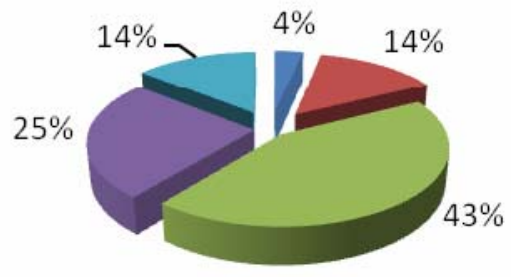

$$
\begin{aligned}
& \text { " não será realizado } \\
& \text { não relevante até o momento } \\
& \text { importante, mas não realizado } \\
& \text { importante e realizado } \\
& \text { muito importante e atualizado }
\end{aligned}
$$

\section{ScoreCard ${ }^{1}$ \\ Gráfico 2- Controle do Alinhamento da TI com base no Balance}

Fonte: dados da pesquisa

Contudo, nota-se pelas respostas, que cerca de $40 \%$ dos executivos apenas entendem a importância dos indicadores e fazem uso dos mesmos. Muito poucos (14\%)

\footnotetext{
${ }^{1}$ Metodologia de avaliação e desempenho de empresas, proposta por Robert Kaplan e David Norton, que utiliza a TI e enterprise resources planning (ERP) como soluções de apoio à gerência de serviços e resultados do negócio.
} 
O desenho da gestão da tecnologia da informação nas 100 maiores empresas na visão dos executivos de TI

têm a preocupação de atualizar continuamente os indicadores de alinhamento, mas para a maioria (61\%), os indicadores não estão ainda fazendo parte de suas agendas de alinhamento.

Outras evidências da realidade do alinhamento das atividades de TI com as de negócio aparecem na indagação da adequação dos processos de TI aos processos de negócio de forma a atender melhor as necessidades das áreas de negócio. As respostas estão sintetizadas no (Gráfico 3).
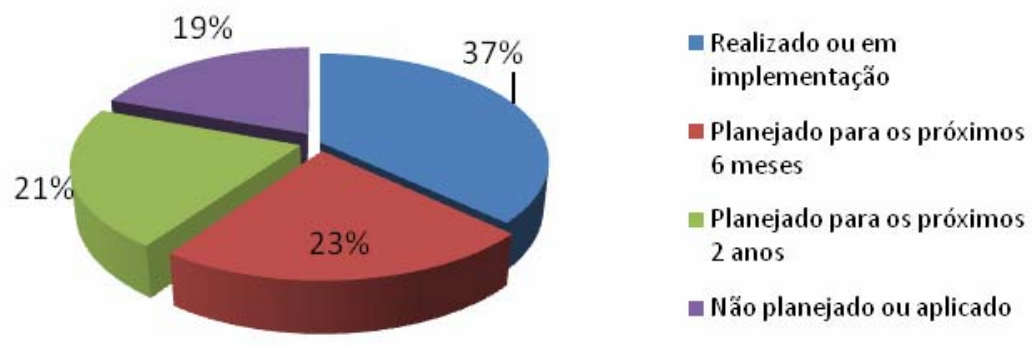

\section{Gráfico 3- Redesenho/Readequação dos processos de TI}

Fonte: dados da pesquisa

Observa-se neste gráfico, que uma parcela ainda baixa (44\%) dos executivos planeja a readequação dos processos de TI aos do negócio e pouco menos de $20 \%$ nem planejam fazê-lo. Apenas 37\% fizeram ou estão fazendo o redesenho de seus processos para adequá-los às demandas do negócio.

\subsection{Gestão de TI}

A gestão das atividades de TI foi examinada dentro do conceito de maturidade dos processos de TI. Os achados indicam haver aí três áreas de preocupação para os executivos de TI. Uma se refere à gestão das demandas, isto é, à gestão das solicitações das áreas de negócio. A segunda, à gestão da produção ou operações das atividades e projetos de TI. E a terceira, à gestão de ativos, incluindo base de dados e infra-estrutura. As respostas dos executivos estão sintetizadas no Gráfico 4. Em seu conjunto, as respostas espelham o grau de maturidade em gestão de TI existente nas empresas pesquisadas. 


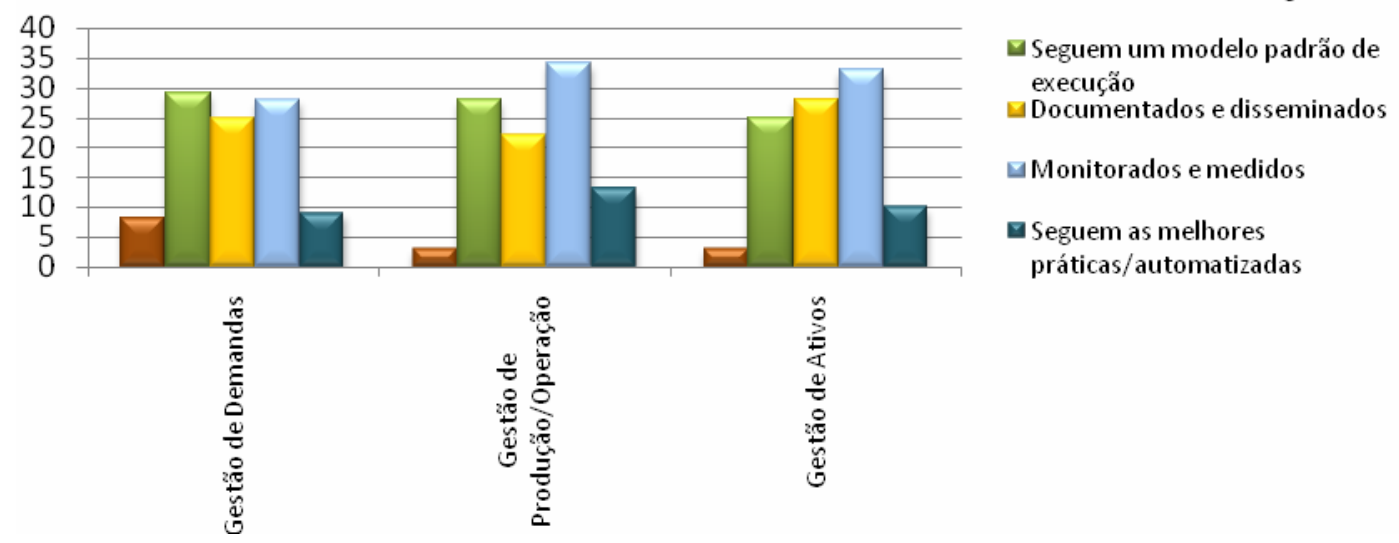

Gráfico 4.- Maturidade dos processos de gestão

Fonte: dados da pesquisa

O que se observa pelas respostas no Gráfico 4 é que de forma razoavelmente coerente, uma parcela pequena dos executivos de TI (menos de 1/3) diz que, em termos de gestão, obedece a um modelo padrão de observância de processos e que seus processos são documentados e medidos. Esse comportamento é observado uniformemente nas três áreas foco da gestão em TI (demanda, operações e ativos). Com implicações maiores para a eficácia da gestão da TI, observa-se que apenas um pequeno percentual dos executivos (entre 8\% e 13\%) segue as melhores práticas (e práticas essas automatizadas) do mercado para seus processos de gestão.

Em processos de gestão da TI, questionou-se também os executivos acerca dos modelos estruturais de gestão da TI utilizados. Individualmente, ITIL (Information Technology Infra-structure Library) foi apontado como o modelo estrutural ou sistema de padronização de processos e atividades de TI mais adotado pelos seus executivos. $\mathrm{O}$ Gráfico 5 mostra a preferência pelos modelos.

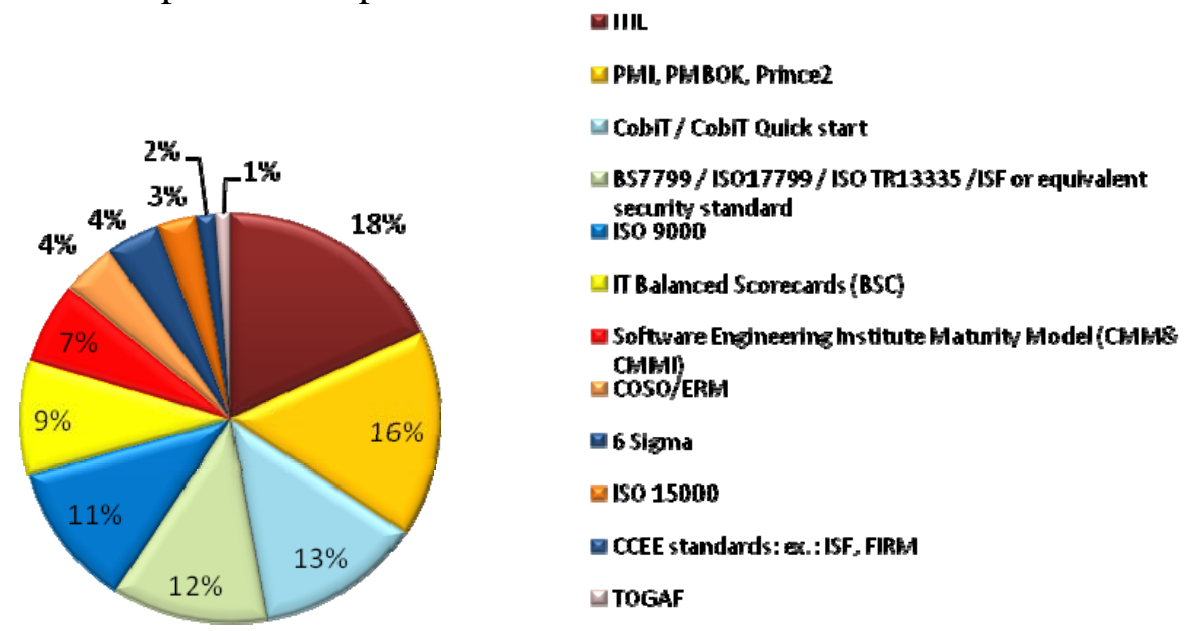

\section{Gráfico 5- Estruturas/Processos de Gestão}

Fonte: dados da pesquisa 
O desenho da gestão da tecnologia da informação nas 100 maiores empresas na visão dos executivos de TI

No conjunto, parece que ITIL, PMI, CobiT e ISO gozam da preferência da maioria absoluta dos executivos de TI. Uma das mais recentes metodologias para a gestão da TI como um negócio, o The Open Group Architecture Framework - TOGAF (2009) - é praticamente ignorado pelos executivos de TI (1\%). Talvez por ser ainda uma prática de gestão recente de arquiteturas e processos, apesar de já estar em sua nona edição.

Outro processo que espelha o formato de gestão da TI nas empresas pesquisadas é a gestão dos custos da TI. A lógica de rateio esperada entre as unidades usuárias da $\mathrm{TI}$, nem sempre é observada e nuanças próprias aparecem ao longo da pesquisa. (O Gráfico 6) mostra os diferentes formatos de absorção dos custos da TI.
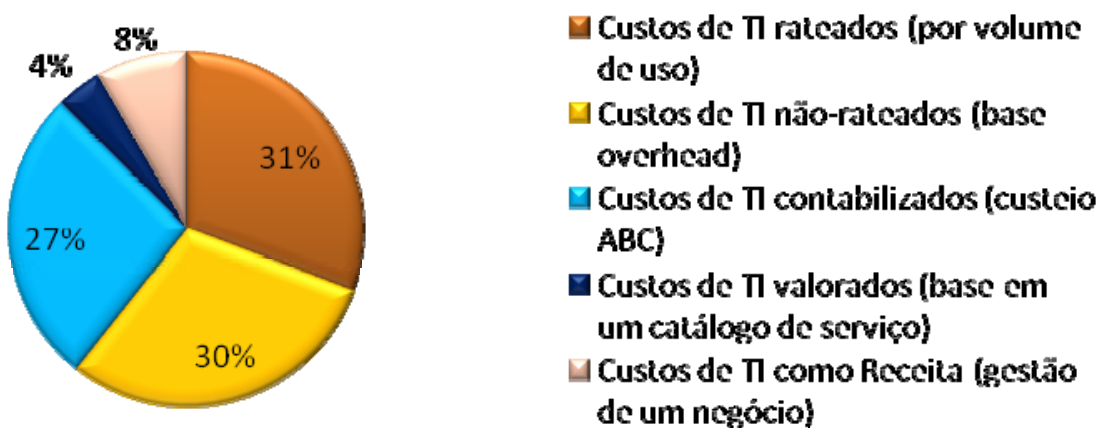

\section{Gráfico 6 - Atribuição de custos de TI}

Fonte: dados da pesquisa

Neste Gráfico, as respostas indicam que em pouco mais de 2/3 das empresas pesquisadas, as despesas da TI não são rateadas diretamente ao longo dos usuários. Em aproximadamente $83 \%$ das empresas que não rateiam os custos da TI (ou 57\% do total das empresas), os custos são pagos por overhead ou são contabilizados à parte (ABC).

Em termos de orçamentação, a gestão de TI mostra um certo padrão de comportamento gerencial, centrado em três evidências significantes.

Primeiro, parece haver uma preferência por alocação de recursos (até 10\%), pela maioria dos executivos de TI, ao longo de tecnologias em andamento, atualização do parque, treinamento e inovação tecnológica (Gráfico 7).

descontados do orçamento de TI. 


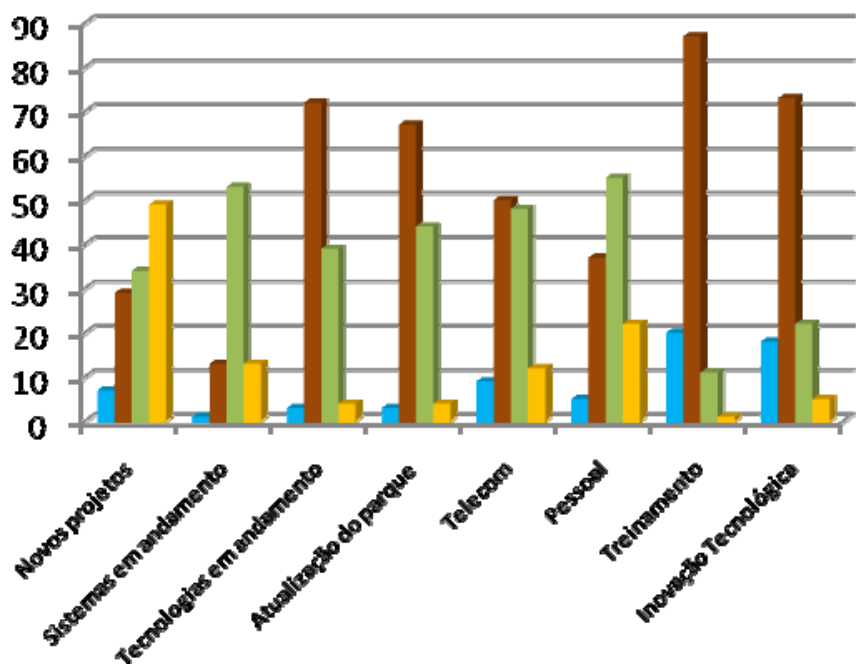

- $0 \%$

atc̉ 10\%

antre $11 \mathrm{e} 25 \%$

acima de $26 \%$

Gráfico 7.- Distribuição do Orçamento de TI

Fonte: dados da pesquisa

Segundo, um conjunto menor de executivos projeta despender em média $20 \%$ de seu orçamento em sistemas e tecnologias em andamento, em atualização do parque, em comunicação e em pessoal. Terceiro, um pequeno grupo (entre $10 \%$ e $20 \%$ ), mas dado ao fato de que os números referem-se às 100 maiores empresas do país, esse percentual passa a ser significativo, não pretende investir, ou tem orçado valor zero para treinamento e inovação tecnológica. Novos projetos é o que recebe a maior taxa de investimentos no orçamento de quase $50 \%$ dos executivos de TI.

No orçamento é relevante ainda a forma como é tratada a terceirização pelos executivos de TI. Por ser um coadjuvante importante, tanto em nível de soluções prontas, quanto em nível de custos para a gestão de TI, a terceirização não pode ser desprezada ou vista como matéria subjacente. Apesar da pronunciada tendência das grandes empresas internacionais em adotarem a terceirização como uma alternativa estratégica para a gestão eficaz da TI (KAPLAN et al., 2004), ainda 13\% dos executivos de TI das empresas pesquisadas destinam orçamento zero para a terceirização. A grande maioria destina até $10 \%$, mas $42 \%$ deles já destinam acima de $10 \%$ de seu orçamento para essa atividade.

Questionou-se ainda os executivos acerca de suas preocupações com a gestão de contratos dos projetos e atividades terceirizados. Observa-se que cerca de $50 \%$ deles de fato realizam a gestão desses contratos, mas apenas $20 \%$ dão a devida atenção, realizando e atualizando seus processos.

É notável ainda nas respostas, que pouco mais de $30 \%$ não realiza a gestão de tais contratos ou mesmo os considera não importantes. Pode-se supor que nessas empresas, a gestão dos contratos pode estar sendo feita por outra área, como o Departamento Jurídico. Ou, o que seria menos provável, os executivos de TI supõem auto-suficiência de seus sistemas em uso e novas aplicações são desenvolvidas internamente, sob encomenda, sem auxílio externo. 
O desenho da gestão da tecnologia da informação nas 100 maiores empresas na visão dos executivos de TI

\subsection{Serviços (Entrega)}

As atividades ou serviços da TI, conhecidos também simplesmente como Entrega, estão aqui explorados sob três vetores mais relevantes achados na pesquisa: arquitetura e sistemas, serviços, e inovação. Arquitetura e sistemas referem-se à operação e manutenção da infra-estrutura de TI, dos sistemas e aplicativos nela existentes. Os serviços referem-se aos serviços comuns executados pela TI, como impressão, comunicações, telefonia e apoio a usuário. Inovação, por sua vez refere-se, grosso modo, a projetos de busca e viabilização de novos equipamentos ou aplicativos que possam alterar positivamente os processos e transações correntes da empresa.

Em termos de arquitetura e sistemas, é mais evidente que cerca de 1/3 dos executivos de TI monitora e mede essa tarefa (operações de arquitetura e sistemas), no sentido de garantir que a TI como um todo funcione adequadamente para os negócios. O (Gráfico 8) apresenta como a TI entrega Arquitetura e Sistemas nas empresas pesquisadas.

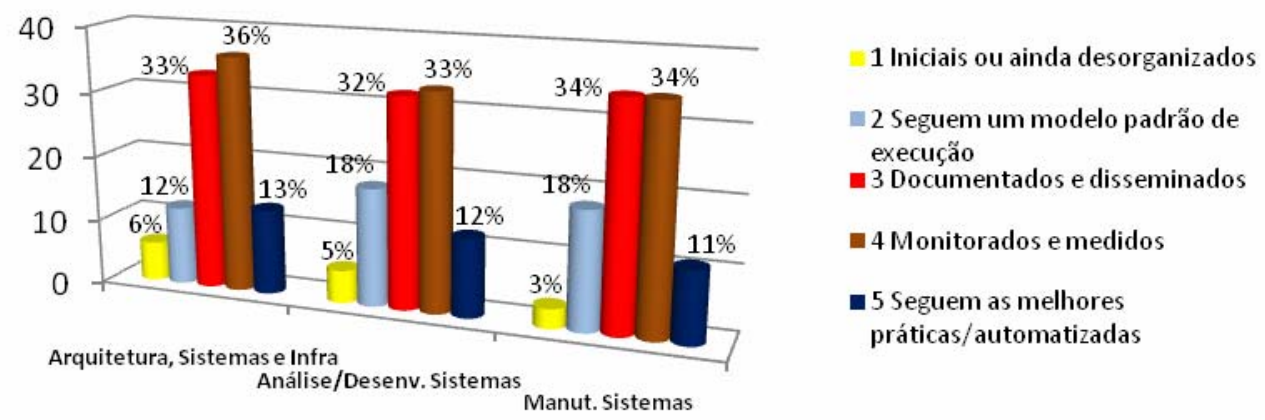

\section{Gráfico 8 - Entrega de Serviços - Arquitetura e Sistemas}

Fonte: dados da pesquisa

Nos serviços de Arquitetura e sistemas, não se pode deixar de notar que, entre os executivos pesquisados, uma parcela muito pequena (11-13\%) indica usar as melhores práticas do mercado e de forma automatizada. Em relação aos serviços gerais da TI, o padrão é basicamente o mesmo, isto é, a TI documenta, monitora e mede, mas parece ainda ter certa dificuldade em adotar as melhores práticas do mercado. O (Gráfico 9) ilustra as informações. 


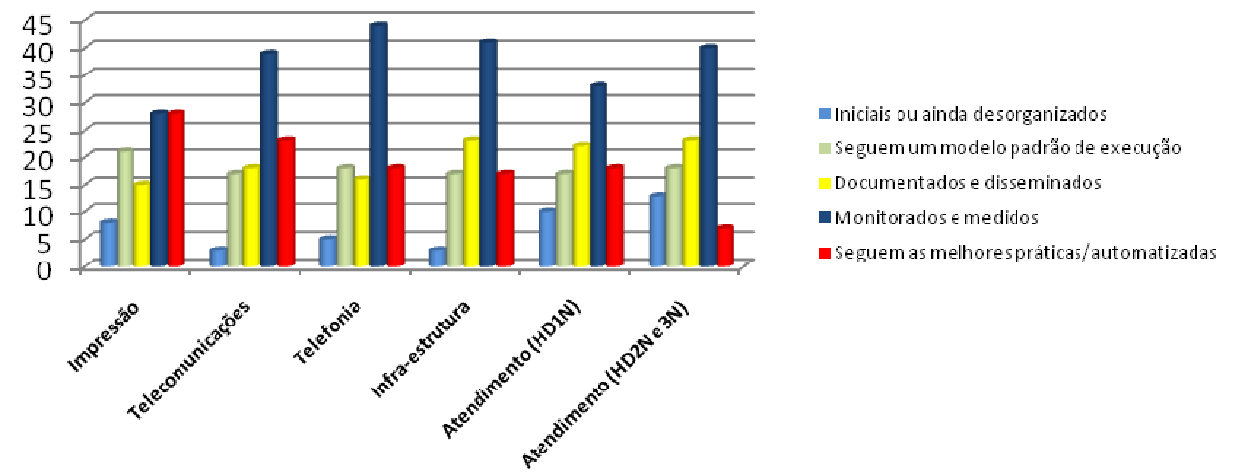

\section{Gráfico 9 - Entrega de Serviços - Comunicação e Apoio}

Fonte: dados da pesquisa

Um baixo percentual de executivos (em média 18\%) garante seguir um modelo padrão de execução, documentando e disseminando os processos e a entrega desses serviços. Uma taxa bem maior deles (em torno de 35\%), contudo, indica monitorar e medir a entrega dos serviços mais comuns.

O terceiro elemento da Entrega da TI foi a Inovação. Aqui procurou-se saber qual o nível de preocupação com a inovação dos executivos de TI, como a TI encara a inovação e o que a TI entrega de inovação para os negócios das empresas. A pesquisa mostrou que pouco mais de $1 / 3$ (35\%) dos executivos dedicam de $5 \%$ a $10 \%$ de seu tempo à busca de inovação. Outro 1/3 dedica-se entre 10\% e 20\%. Do restante, cerca de 20\% dedicam apenas até 5\% de seu tempo à inovação.

Quando se olha o papel da TI no processo de inovação observa-se que para quase 2/3 dos executivos da TI, o papel desta na inovação deve ser mais de parceria com os executivos de negócio do que de liderança da inovação. O (Gráfico 10) mostra as respostas.

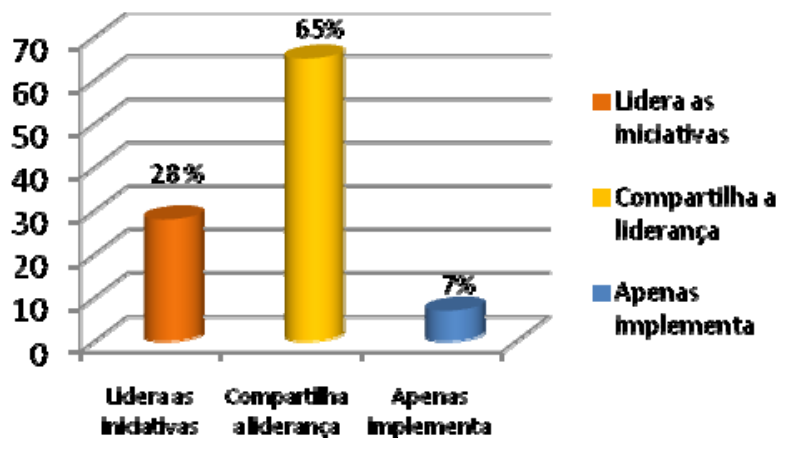

\section{Gráfico 10 - Papel da TI na Inovação}

Fonte: dados da pesquisa

Ainda em relação aos projetos e tecnologias que a TI está entregando para a 
O desenho da gestão da tecnologia da informação nas 100 maiores empresas na visão dos executivos de TI

empresa ou para a área de negócio desta, a pesquisa indica que a maioria dos executivos de TI (51\%) ainda está planejando ou de fato não planeja entregar qualquer projeto de inovação. O (Gráfico 11) sintetiza as respostas para esta faceta da Entrega de inovação.

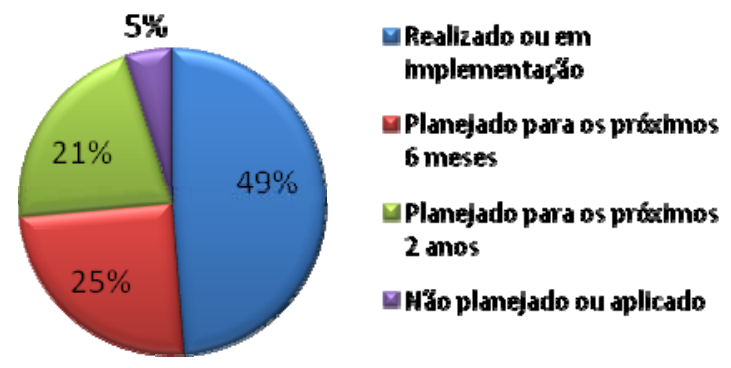

\section{Gráfico 11- Projetos de Inovação e Tecnologias}

Fonte: dados da pesquisa

Em síntese, esses foram os principais achados no item Serviços ou Entrega. O quarto aspecto do mapa das principais tendências do gerenciamento da TI nas maiores empresas sediadas no Brasil, refere-se à Qualidade. Discute-se a seguir os principais neste item.

\subsection{Qualidade e Segurança em TI}

As dimensões Qualidade e Segurança são aqui avaliadas em termos dos principais resultados obtidos, que conformam o gerenciamento da TI nas empresas pesquisadas: a gestão de serviços, relações com o negócio, controles internos e segurança da informação. A gestão de serviços observa tanto como são tratados os fatores elementares da rotina da gestão da TI (incidentes, problemas, mudanças, configurações, capacidade e disponibilidade), quanto é garantida a continuidade dos serviços de TI para os negócios da empresa. As relações com o negócio são vistas em termos de existência de indicadores de desempenho dos negócios. Os controles internos referem-se à existência de controles e níveis de eficácia dos mesmos. Segurança de informação explora a existência de política e de dispositivos que possam garantir a integridade e confidencialidade das informações. 
O (Gráfico 12) mostra como são tratados os serviços de rotina pela TI. Da mesma forma que nas dimensões anteriores, parece haver uma grande preocupação em documentar, monitorar e medir o tratamento dos incidentes, problemas, configurações, que dizem diretamente respeito à segurança dos sistemas de informação. Fica também evidente que os executivos de TI seguem um modelo padrão de execução, que provavelmente é um modelo interno, mas a pesquisa mostra que parece haver, novamente, pouca preocupação em seguir as melhores práticas automatizadas de gerenciamento da qualidade dos serviços de TI.
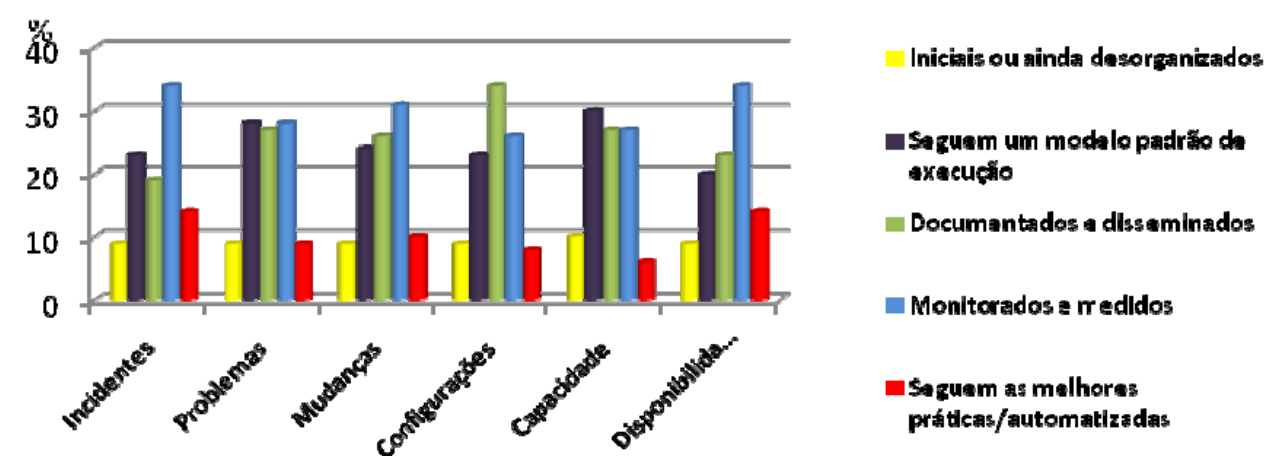

\section{Gráfico 12 - Gestão de Serviços}

Fonte: dados da pesquisa

Em termos de sua relação com os negócios, a pesquisa mostra que $76 \%$ deles informam conhecer os indicadores e metas do negócio, mas apenas $41 \%$ possuem indicadores de qualidade que alimentam os indicadores de negócio. Ademais, 39\% deles apenas indicam gerar relatórios diários com indicadores de desempenho dos negócios.

Com relação aos Controles Internos (Gráfico 13), pode-se observar dois fatos de relevância nas respostas dos executivos. De um lado, acima de 75\% deles informam que formalizam e documentam os controles internos para garantia da qualidade e segurança de seus serviços.

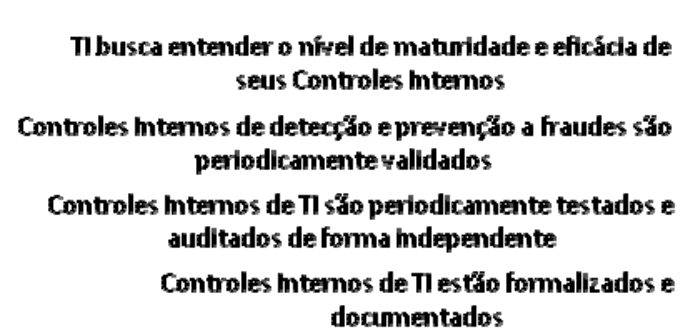
documentados

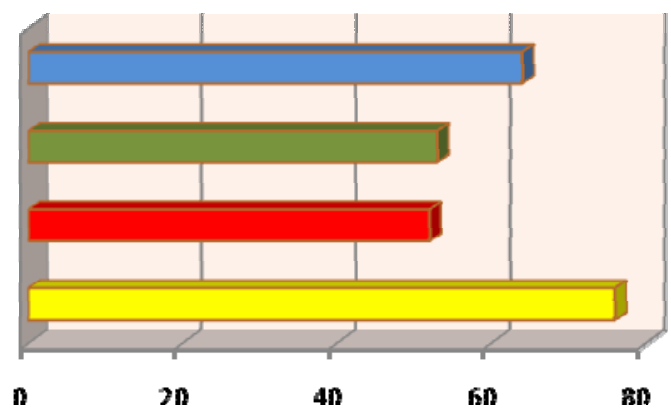

\section{Gráfico 13 - Controles Internos}

Fonte: dados da pesquisa 
O desenho da gestão da tecnologia da informação nas 100 maiores empresas na visão dos executivos de TI

De outro, cerca de $50 \%$ dos executivos apenas afirmam validar e auditar periodicamente seus controles internos. Apesar de ser significante a taxa dos que julgam importante as implicações para a maturidade de seus controles (64\%), esta taxa ainda parece ser relativamente baixa, dada a sua importância como fator de garantia para a qualidade e segurança dos serviços de TI.

\section{CONCLUSÕES}

O desenho da gestão de TI pelos executivos de TI das 100 maiores empresas sediadas no Brasil mostra um quadro bastante próximo daquele observado na literatura, determinado pelos executivos das grandes empresas mundiais. Em resumo, pode-se dizer que a TI é gerida pela maioria dos executivos de TI no Brasil mais como um sistema fornecedor de soluções do que como um sistema gerador de inovações e muito menos como um sistema quebrador de regras do negócio, na taxonomia de Craig; Tinaikar (2006).

Especificamente no Brasil, os executivos de TI desenham o gerenciamento da TI para aparentemente alinhar-se aos negócios. Há, porém, uma grande lacuna entre a realidade e o que eles desejam. Enquanto a grande maioria (63\%) diz ter um plano de alinhamento, uma parcela significativa deles (40\%) não o reconhece como importante. Isso leva a uma realidade de subordinamento da TI ao negócio, onde a grande maioria dos executivos de TI não tem desenhado sua área para fazer o controle do alinhamento com indicadores de negócio, como por exemplo, o uso do Balanced ScoreCard. A readequação de seus processos aos de negócios é plano apenas para o futuro.

Quanto à dimensão "gestão", todos os executivos adotam um modelo de práticas gerenciais (ITIL, COBIT, PMI, BS7799, ISO9000) para gerir seus processos de demanda, operações e ativos. ITIL é o mais adotado (quase $50 \%$ ) pelos executivos de TI. Isso mostra um desenho da TI para documentar e monitorar seus processos internos como modelos padrões, obliterando a criação de estruturas automatizadas na TI, com base nas melhores práticas do mercado. Os custos da TI estão desenhados para serem contabilizados sob três modelos básicos: rateio por volume, overhead e custo ABC. Os orçamentos de TI estão desenhados para contemplar, em volume menor ou mediano, sistemas e tecnologias em andamento, atualização do parque, comunicação, treinamento e inovação tecnológica. Novos projetos recebem a maior taxa de investimentos, ainda que por um pequeno grupo de empresas. A terceirização está desenhada na maioria dos orçamentos como item complementar (alguns recebem cota zero), merecendo não mais do que $10 \%$ do orçamento da TI. Talvez por isso, apenas $50 \%$ dos executivos de TI administram tais contratos diretamente.

Os executivos de TI têm desenhado suas áreas para garantir o funcionamento dos serviços ou a entrega da arquitetura e sistemas por meio de controles documentados, monitorados e medidos. Novamente aqui parece terem se descuidado de considerar em seus desenhos, as melhores práticas automatizadas do mercado. Os serviços comuns da TI (impressão, comunicação, apoio usuário) são mais monitorados e medidos do que organizados, padronizados, documentados e disseminados. A gestão da TI está desenhada para consumir mais tempo dos executivos com as tarefas de rotina do que com a inovação, que parece não ser prioridade entre eles, pois mais planejam projetos de inovação para o futuro do que os executam presentemente. Executivos das 
empresas pesquisadas preferem mais adotar a parceria na liderança da inovação na empresa do que assumir um papel de líder proativo.

Por fim, os executivos têm desenhado claramente seu modelo de gestão de processos (ITIL, COBIT, etc.), garantindo padrões internos, documentação, monitoramento e medida dos indicadores de qualidade, mas ainda se distanciam das melhores práticas automatizadas do mercado. Seus processos são voltados para a TI e ainda não possuem, nem tampouco fornecem indicadores de desempenho para os negócios. Por isso, possuem controles internos de qualidade, mas poucos ainda os validam ou auditam-nos externamente.

\section{REFERÊNCIAS}

BLOKDIJK, Gerald; MENKEN, Ivanka. (2008). Software Testing and Quality Assurance. Emereo Pty Ltd. Disponível: isbndb.com/d/publisher/emereo_pty_ltd.html. Acesso: 25/04/09.

CRAIG, David, KANAKAMEDALA, Kishore, TINAIKAR, Ranjit. (2007). The Next Frontier in IT strategy: A McKinsey Survey. McKinsey Quarterly. Disponível em: http://www.mckinseyquarterly.com/Information_Technology/The_next_frontier_in_IT_ strategy_A_McKinsey_Survey. Acesso em: 26/02/2009.

CRAIG, David; TINAIKAR, Ranjit. (2006). Divide and Conquer: Rethinking IT strategy. McKinsey Quarterly. Disponível em: http://www.mckinseyquarterly.com/Divide_and_conquer__Rethinking_IT_strategy. Acesso em: 26/02/09.

FARRELL, Diana; TERWILLIGER, Terra; WEBB, Allen P.(2003). Getting IT spending right this time. Disponível em: www.mckinseyquarterly.com/Information_Technology/

Management/Getting_IT_spending_right_this_time. Acesso em: 25/02/09.

FAGUNDES, Eduardo M. (2009). Cobit - Um kit de ferramentas para gestão de TI. Disponível em: http://www.efagundes.com/Artigos/COBIT.htm. Acesso em: 20/04/09.

KAPLAN, James M., LÖFLER, Markus, ROBERTS, Roger P. (2004). Managing Next Generation Infra-structure. McKinsey on IT, 3, p. 1-9.

LAARTZ, Jurgen; MONNOYER, Eric, SCHERDIN, Alexander. (2003). Designing IT for Business. McKinsey Quarterly, 3, p.77-84.

LUTCHEN, Mark. (2003) Managing IT as a business: a survival guide for CEOs. Hoboken (NJ): John Wiley and Sons.

MAHONEY, John.(2007). Critical Actions for the Transition of IT Organizations: 2007-2008. Gartner Technology Business Research Insight. June 14.

MARWAHA, Sam; SETH, Parul, TANNER, David W. (2005). What Global Executives 
O desenho da gestão da tecnologia da informação nas 100 maiores empresas na visão dos executivos de TI

Think About Technology and Innovation. McKinsey Quarterly. Disponível em: http://www.mckinseyquarterly.com/What_global_executives_think_about_technology_ and_innovation_1653 Acesso em: 25/02/09.

MARWAHA, Sam; WILLMOTT, Paul. (2006). Managing IT for Scale, Speed and Innovation. McKinsey Quarterly. September, p. 15-21. Disponível em: http://www.mckinsey

quarterly.com/Managing_IT_for_scale_speed_and_innovation_1848. Acesso em: 25/02/09.

PRAHALAD C.K. (2006). CIOs Hold Key to Operational Excellence. Optimize. v.5, n.5, p.66.

PRAHALAD, C.K. KRISHNAN, M.S. (2002). The Dynamic Synchronization of Strategy and Information Technology. MIT Sloan Management Review, 43(4), p. 24-33.

ROBERTS, Roger; SIKES, Johnson. (2008). IT's Unmet Potential. McKinsey Quarterly - Survey on Information and Technology Strategy. Novembro, 9 p. Disponível em: http://www.mckinseyquarterly.com/ITs_unmet_potential_McKinsey_Global_Survey_R esult_2277. Acesso em: 25/02/09.

SHPILBERG, David.; BEREZ, Steve, PURYEAR, Rudy; SHAH, Sachin. (2007). Avoiding the Alignment Trap in Information Technology. MIT Sloan Management Review, 49(1), p. 51-58.

SMITH Heather A.; MCKEEN, James D. IT in 2010: The Next Frontier. MIS Quarterly Executive. v. 5, n.3, p.125-136, 2006.

TAKANEN, Tiina. (2008). The Changing Role of the CIO - Is CIO and IT expert or a Business Executive? Disponível em: http://hsepubl.lib.hse.fi/FI/ethesis/pdf/12001/hse_ethesis_12001.pdf. Acesso em: 6/11/2009.

TOGAF. (2009). TOGAF Version 9. Zaltbommel (NL): Van Haren Publishing.

WEILL, Peter; ARAL, Sinan. (2006). Genereting Premium Returns on your IT Investments. MIT Sloan Management Review, 47(2), p. 39-48.

WEILL, Peter; SUBRAMANI, Mani; BROADBENT, Marianne. Building (2002). IT Infra-structure for Strategic Agility. MIT Sloan Management Review, 44(1), p.57-65. 
Rodrigues, L. C., Maccari, E. A., Simões, S. A.

R. Gest. Tecn. Sist. Inf. /JISTEM Journal of Information Systems and Technology Management, Brazil 